\title{
El estudio de una opinion estadounidense desde la dimensión del género y su utilidad para la traducción jurídica
}

\section{(Study of a us opinion from the genre dimension and its application to legal translation)}

\author{
LAURA VEgara FABREGAT \\ Ivegara@um.es \\ Universidad de Murcia
}

Fecha de recepción: 29 de marzo de 2016

Fecha de aceptación: 9 de mayo de 2016

Resumen: El estudio del género se revela a menudo como un paso necesario para la práctica de la traducción en general (Swales, 1990; Bhatia, 1993; Borja, 2000; Munday, 2004; Alcaraz, Campos \& Miguélez, 2001). En consecuencia, no es de extrañar que para las traducciones especializadas, como la jurídica, el análisis del género sea una herramienta previa básica. En el presente trabajo nos proponemos analizar de manera sucinta y desde la dimensión del género textual un género jurídico: una opinion o sentencia del Tribunal Supremo estadounidense. Este análisis nos mostrará algunas asimetrías de diverso tipo existentes entre ambas sentencias y pondrá de relieve algunos datos relevantes pertenecientes a la cultura jurídica de fondo en cada caso. Los aspectos derivados de dicho análisis pueden ser de interés para el traductor jurídico (trabaje o no con sentencias específicamente), el cual debe indagar en el texto que debe traducir para poder transmitir todos los matices tanto explícitos como implícitos (Orts, 2014).

Palabras clave: Inglés jurídico, Opinion, Traducción jurídica, Tribunal Supremo de los Estados Unidos.

Abstract: The study of the text genre is undoubtedly very relevant for the work of translators in general (Swales, 1990; Bhatia, 1993; Borja, 2000; Munday, 2004; Alcaraz, Campos \& Miguélez, 2001). Thus, it is certainly essential when we are within a specialized area, such as the legal area. Our purpose here is to briefly analyse a legal genre, a US opinion, from the genre perspective. The analysis referred to will reveal interesting asymmetries between the two abovementioned types of document and will 
also provide an attractive insight into the mentioned American genre. The conclusions of the study may be of assistance for legal translators in general and for those working with judicial texts, amongst others.

Keywords: Legal English, Opinion, Legal translation, U.S. Supreme Court.

\section{IINTRODUCCIÓN}

Sin duda, la tarea traductológica es, en general, ardua y compleja, pues cuenta con diversos condicionantes que van variando según el área profesional o específica en la que nos encontremos, ya sea esta económicacomercial, audiovisual, turística, médico-científica o periodística, entre otras. Los textos jurídicos no escapan a este fenómeno, ya que pertenecen a un campo del saber que presenta muchos escollos y complejidades de diversa índole. En este contexto, creemos que el estudio del género es un paso clave para todo aquel traductor que se enfrenta a un texto por primera vez, ya que tiene casi la mitad de la labor realizada quien se haya familiarizado con la macroestructura, la función comunicativa o las convenciones léxicas de los géneros jurídicos (Alcaraz, Campos \& Miguélez, 2001: 119). Como argumento adicional a favor del estudio previo del género textual, encontramos el hecho de que determinar la tipología textual, la función y el propósito del texto ayuda en gran medida al traductor a decidir la jerarquía de los niveles de equivalencia (Hatim \& Munday, 2004: 286).

En la parte central de nuestro trabajo, nos proponemos realizar un análisis de lo que consideramos un género o un subgénero muy concreto de la sentencia anglosajona: la opinion o sentencia del Tribunal Supremo estadounidense. De la tradición jurídica anglosajona deriva inevitablemente el derecho estadounidense, aunque este último posea sus rasgos propios y peculiares (Séroussi, 1998: 82). Por ello, y por la relevancia y las repercusiones que poseen todos los cambios y avances que se producen en dicho país, nos centraremos para el análisis en uno de sus géneros clave. Las reflexiones derivadas de este escrutinio pueden ayudar al traductor a abundar en la forma y el contenido del texto original a traducir. Asimismo, pueden ser de utilidad para traductores jurídicos que se enfrenten a documentos o a rasgos similares a los que aquí describimos, entre otros.

No obstante, hemos de adelantar que nuestro estudio no dará como resultado una serie de datos cuantitativos, sino un conjunto de reflexiones resultado de un análisis cualitativo de un documento, el cual seguirá unos pasos o fases que describiremos en el apartado dedicado a la metodología. El fin último de todo ello es recalcar la importancia del estudio previo del género en un ámbito especializado como es la traducción jurídica, pues sin duda ayuda al traductor a conocer mejor, no sólo las convenciones formales del documento original a traducir, sino también el mensaje en sí mismo (y su 
trasfondo), cómo este se ha desarrollado y por qué lo ha hecho de esa manera en particular. El texto jurídico, por ser considerado de naturaleza técnica (en parte al menos, por su terminología, entre otros aspectos), a menudo se enfoca, a la hora de traducirlo, de forma más bien "automática", buscando equivalentes terminológicos y formales, sin prestar especial atención a otros detalles que pueden influir en el mensaje y que comentaremos aquí.

Este trabajo constará de las siguientes partes: primeramente, abundaremos de manera breve en la noción de género en sí misma. Ciertamente, ya se ha escrito largo y tendido sobre la cuestión, pero consideramos que, siendo el tema central de nuestro trabajo, hemos de exponer al menos los fundamentos principales, así como aquello que se ha comentado en torno al género y la traducción jurídica en concreto. En segundo lugar, hablaremos, también de manera resumida, de los rasgos y las convenciones que suelen mostrar las sentencias tanto en España como en los Estados Unidos, así como de la opinion como género.

Posteriormente, indicaremos de manera breve la metodología que hemos seguido para el estudio del género en el que pretendemos centrarnos. Se trata de un tipo de texto muy particular y culturalmente marcado, cuyo escrutinio revelará sin duda similitudes y diferencias respecto de la sentencia, así como del estilo de redacción jurídica español. Una vez descrita la metodología, daremos paso al análisis cuyos resultados o conclusiones preliminares perfilaremos en las conclusiones finales, que cerrarán el presente artículo.

Antes de comenzar, nos parece interesante describir de manera sucinta la institución que emite la opinion que analizaremos, a modo de contexto: El Tribunal Supremo de los Estados Unidos. Se trata de la instancia judicial más alta del país, competente en todos los casos estipulados por la Constitución y las leyes estadounidenses. En pocas palabras, se podría decir que es el guardián e intérprete primordial de la Constitución (Dickerson, 1996: 377). La función básica de este Tribunal es velar por la constitucionalidad de las resoluciones judiciales (facultad denominada judicial review). Una institución española que se asemeja bastante en importancia y funciones al Tribunal Supremo estadounidense sería el Tribunal Constitucional. Con sede en Madrid, este tribunal cuenta con doce miembros y es, como en el caso del Tribunal Supremo estadounidense, el intérprete máximo de la Constitución del país (art.1 LOTC). No obstante, hemos de hacer hincapié en que no se trata de tribunales totalmente equivalentes, ya que presentan algunas diferencias sustanciales en las que no nos detendremos aquí por motivos de espacio. 


\section{LA NOCIÓN DE GÉNERO \\ Cuando hablamos del concepto de género, no podemos dejar de citar a Swales (1990) y a Bhatia (1993), sobre todo. Según Swales, el género constituye un compendio de casos o eventos comunicativos cuyos participantes comparten una serie de propósitos de comunicación (1990: 58). Nos gustaría mostrar la definición completa de género de Swales, tras haber sido matizada posteriormente por Bhatia: \\ It is a recognizable communicative event characterized by a set of communicative purposes identified [...] by the members of the professional or academic community [...]. Most often it is highly structured and conventionalized with constraints on allowable contributions in terms of their intent, positioning, form and functional value (Bhatia 1993: 13).}

Expresado de manera muy abreviada, podemos afirmar que para Bhatia el género es un ejemplo de haber logrado un propósito comunicativo mediante el conocimiento convencionalizado de recursos lingüísticos y discursivos (1993: 16). Cada género estructuraría un fragmento de experiencia o de realidad de una manera determinada. Al recurrir a otro género diferente, lo que estaríamos haciendo es estructurar el mismo fragmento de otra manera.

En el contexto del derecho, Anabel Borja (2007: 144) define los géneros textuales como una serie de patrones rígidos y repetitivos provenientes de una cultura jurídica heredada, de los hábitos profesionales, de los usos sociales y de la formación académica. Además, un género:

"[...] conforma una selección de contenidos, una manera de exponer los hechos, una retórica y una percepción del mundo que aparecen plasmados de forma inequívoca en cada realización textual del ámbito jurídico. Si a esta realización textual concreta le sumamos un objetivo comunicativo claro o una función jurídica específica, el resultado es el concepto de género jurídico." (Ibíd.)

Para el traductor el análisis de los géneros aporta una información en gran medida valiosa por varias razones: aparte de la descripción lingüística ya mencionada, permite llegar a conclusiones globales que recogen aspectos socioculturales e incluso psicológicos (Bhatia, 1993). Una descripción de esta índole puede ser de utilidad, por ejemplo, para la compresión y elaboración de los géneros académicos (y quizá también para su traducción) porque "[...] not only clarifies the communicative goals of the discourse community in question, but also the individual strategies employed [...]" (1993: 39). 
Resulta innegable que la tarea de enfrentarnos, por ejemplo, al trasvase de una escritura de compraventa, será más sencilla, si previamente nos hemos tomado la molestia de extraer, describir y almacenar sus principales características (p.ej., léxico, principales cláusulas, etc.). Ahorraremos tiempo y esfuerzo, pues ya conocemos sus características y convenciones. Creemos, pues, que el estudio del género se constituye como una herramienta de gran utilidad para el traductor: le facilita la tarea y le ayuda a ser más eficaz en su trabajo (Cobos, 2009), no sólo porque haya almacenado una serie de apartados y rasgos, sino porque, como hemos señalado anteriormente, al analizar dichos rasgos está al mismo tiempo profundizando en el mensaje que debe traducir, en su contexto y en las ideas subyacentes que quizá a primera vista no se perciben.

Sin embargo, hemos de indicar también que hay expertos que sugieren que solo un escaso porcentaje de las decisiones de un traductor dependen de factores como la función o el género (Mayoral, 2000: 5), pero creemos que este tipo de opiniones no son las predominantes. Ciertamente, la tendencia parece ser la de considerar el estudio del género como algo valioso, pues hay diversas investigaciones que ya han aplicado la herramienta del análisis del género a la traducción especializada (García Izquierdo, 2007); en concreto, en el campo del derecho hay varios casos respecto de diferentes combinaciones de idiomas (Barceló, 2009, francésespañol; Orts, 2014, inglés-español, entre otros). Por ejemplo, Borja (2007), mencionada más arriba, aporta en su trabajo una interesantísima descripción de la evolución de la teoría general de los géneros y un estudio de los géneros jurídicos, entre otras cosas (2007: 144).

En suma, nos parece que el estudio del género textual es un aspecto provechoso que repercute directamente en la tarea traductológica y determina una serie de decisiones que afectan a la elaboración de la traducción final. Por ello, nuestro objetivo principal en el presente estudio es describir y analizar brevemente, mediante la herramienta del género, un tipo de documento jurídico muy concreto: la sentencia del Tribunal Supremo estadounidense, también denominada opinion. Si bien la opinion es un género muy específico ceñido a una situación comunicativa concreta, creemos que los comentarios derivados de su análisis (así como el simple proceso de reflexión sobre el mismo) pueden ser de utilidad para el proceso de traducción de sentencias y de documentos jurídicos en general, pues contiene elementos (lingüísticos, pragmáticos, etc.) que pueden estar presentes en otras sentencias e incluso en otros textos de índole jurídica. Con tal fin, aquí nos basaremos parcialmente en Vegara (2013), entre otros autores, pues su investigación gira en torno a las opinions del Tribunal Supremo estadounidense y su traducción inglés-español. 


\section{LAS SENTENCIAS EN LA CULTURA JURÍDICA ESPAÑOLA Y ANGLOSAJONA}

En las secciones que ofrecemos a continuación señalaremos algunas asimetrías lingüísticas, textuales y pragmáticas destacables que la sentencia en España puede presentar respecto de la sentencia anglosajona ( $y$, por ende, la estadounidense), así como las convenciones sobresalientes de ambas. Este preámbulo nos servirá como introducción para después profundizar en la opinion y comprender mejor su escrutinio cuando comentemos sus rasgos y aspectos más peculiares como género per se.

\subsection{Algunas discrepancias generales entre la sentencia española y la anglosajona}

Efectivamente, como señalan varios autores (Álvarez Álvarez, 2008; Orts, 2014, por citar dos casos), existen muchas diferencias de base entre la sentencia española y la anglosajona. En la raíz de estas discrepancias hallamos el hecho de que ambos géneros proceden de culturas muy dispares, con tradiciones históricas y jurídicas muy distintas. El derecho anglosajón y el derecho continental (donde se encuadra el derecho español) provienen de tradiciones epistemológicas sin duda diferentes, ya que el primero posee una tradición eminentemente empírica, basada en el derecho positivo (Radbruch, 1958: 39), mientras que el segundo está más fundamentado en la ley codificada.

Estas diferencias fundamentales se manifiestan en diversos aspectos a nivel lingüístico y pragmático-discursivo. Como apunta Orts (2014) en su estudio de las sentencias del Tribunal Supremo inglés y español (en concreto analiza los recursos de casación), entre otras discrepancias, el documento español presenta una macroestuctura fija y clara, con un nombre poco memorable, pero una gran exactitud en los detalles y la información. La sentencia inglesa es, en cambio, más breve y personal, con una organización estructural menos rígida y una clara identificación (Orts, 2014). En estos y otros aspectos abundaremos un poco más en secciones posteriores de este estudio.

A continuación, analizaremos las características y convenciones más destacadas de la sentencia española para poder comprender mejor sus diferencias y asimetrías con respecto de la sentencia anglosajona, y, en concreto, respecto de la opinion estadounidense.

\subsection{La sentencia española desde la perspectiva del género}

No es de poca importancia el hecho de que la sentencia se erige como el género característico del poder judicial (Álvarez Álvarez, 2008: en línea). Se podría definir a grandes rasgos como el acto de decidir en un proceso. Más específicamente es la "[r]esolución dictada dentro de un procedimiento [...] por el órgano jurisdiccional que conoce del mismo y con 
el fin de decidir finalmente la cuestión sometida a su enjuiciamiento" (Ribó, 2005:1308).

En el ámbito español la sentencia recaería en el área de las resoluciones judiciales. Su estructura principal se divide en: encabezamiento, hechos probados y fundamentos de derecho; estos últimos incluyen los razonamientos que concluyen en el fallo. La sentencia debe hacer constar si es o no firme, qué recursos se pueden interponer contra la misma y ante qué instancia (Guasp, 1956: 549). Por ello, toda sentencia es promulgada en audiencia pública y comunicada a las partes, con el fin de que estas puedan presentar recurso. Este género es susceptible de clasificarse según varios criterios, pero, por motivos de brevedad, solo indicaremos que es una resolución judicial, como se ha señalado más arriba, y que se situaría dentro de los documentos de tipo jurisdiccional (Álvarez Álvarez, 2008: en línea).

En lo relativo a su macroestructura, cuenta, como apuntábamos anteriormente, con una organización más bien rígida y bien definida; además consta de varias partes claramente enlazadas entre sí: encabezamiento; el cuerpo textual que incluye los antecedentes de hecho (o hechos probados) y los fundamentos de derecho; y el fallo (Orts, 2014). Desde el punto de vista funcional la podemos describir de la siguiente manera (Borja, 2000: 70): preámbulo o encabezamiento (función expositiva); antecedentes de hecho y hechos probados (historia del proceso que ha seguido la causa y relato de los hechos, respectivamente, función expositiva); fundamentos de derecho (argumentación jurídica, función argumentativa); y el fallo (función instructiva). Como indicaba Orts (2014), esta esquematización tan nítida no se suele dar en la sentencia típica anglosajona.

Igualmente, podemos ilustrar de una forma más visual la macroestructura de la sentencia española gracias a la propuesta formal con ejemplos que nos proporciona Tomás (2005: en línea):

\begin{tabular}{l}
\hline $\begin{array}{l}\text { a. Lugar, fecha y datos de las partes. Nombres de los abogados o } \\
\text { procuradores. }\end{array}$ \\
\hline ENCABEZAMIENTO \\
\hline Madrid a veintisiete de marzo de dos mil dos, [...]. \\
\hline Visto el recurso contencioso-administrativo que ante esta Sala de la \\
Audiencia Nacional ha promovido la Procuradora de los Tribunales doña \\
Victoria P. M. D. P., en nombre y representación \\
\hline b. Hechos alegados por las partes en párrafos separados y ordenados. \\
\hline ANTECEDENTES DE HECHO \\
\hline PRIMERO El acto impugnado procede del Ministerio de Justicia y es de \\
fecha 27 de septiembre de $2000,[\ldots]$. \\
\hline c. Argumentos y fundamentos legales oportunos para la defensa. \\
\hline
\end{tabular}




\begin{tabular}{|l|}
\hline FUNDAMENTOS DE DERECHO \\
\hline PRIMERO El presente recurso, interpuesto por la representación de doña \\
María Ángeles I. T., tiene por objeto la resolución [...]. \\
\hline SEGUNDO [...] \\
\hline d. El fallo o el acuerdo alcanzado. \\
\hline FALLAMOS \\
\hline $\begin{array}{l}\text { PRIMERO Que debemos desestimar y desestimamos el presente recurso } \\
\text { núm. 03/1441/2000 interpuesto [...]. }\end{array}$ \\
\hline
\end{tabular}

Tabla 1: Basado en Tomás (2005: en línea)

El texto de la sentencia que suele componer las distintas partes de la macroestructura que acabamos de detallar ( $y$ del que no hemos incluido ejemplos por motivos de brevedad) suele mostrar un lenguaje estereotipado y con un alto grado de impersonalidad, que se logra a través de un nutrido uso de la voz pasiva y las nominalizaciones, entre otros recursos (Orts, 2014). También se aprecia un uso complejo de la sintaxis que a veces puede resultar excesivamente intrincada (2014). Ciertamente, una crítica recurrente a las resoluciones judiciales españolas, que a veces es bien merecida, es la falta de claridad (Rodríguez Achútegui, 2005: 1). Dentro de la selección léxica nos parece interesante comentar el aparente rechazo por el uso de la metáfora en el lenguaje jurídico en español, en concreto en las sentencias. De hecho, en opinión de algunos expertos un juez debe: "[...] evitar adjetivaciones excesivas y el uso de metáforas. Y no ha de referirse a mundos imaginarios 0 a cuestiones para las que carece se estricta competencia jurídica. [...] el juez no puede comportarse como un literato, [...]" (Malem, 2006: 63).

En lo relativo a la función comunicativa, podemos afirmar que la función primordial de este género sería la informativa, pues su objetivo comunicativo es transmitir una decisión judicial que resuelve un conflicto entre las partes (Alcaraz, Campos \& Miguélez, 2001: 118-119). En esta línea, cabría decir que en la sentencia estadounidense, por el contrario, predomina la modalidad comunicativa descriptivo-prescriptiva (Cheng \& Sin, 2008: 34-35), aunque este rasgo lo comentaremos más adelante cuando nos centremos en el análisis de la opinion.

\subsection{La sentencia anglosajona desde la perspectiva del género: la opinion}

Comenzaremos la presente sección describiendo la sentencia inglesa, pues es en cierto modo la precursora de la estadounidense. Ante todo, la sentencia inglesa tiene una función primordial en el derecho inglés: a diferencia del juez español, el inglés debe seguir los dictámenes de jueces anteriores (Orts, 2014). Este aspecto se verá reflejado, entre otros, en el rasgo constituido por la intertextualidad de la sentencia, el cual señalaremos más abajo. Hemos de recordar, en primer lugar, que la macroestructura de 
la sentencia anglosajona es menos clara y rígida que la española. Con el fin de ilustrar la organización de este tipo de documento recurriremos a Bhatia (1993:101-136), quien distingue primeramente entre legislative provisions y legal cases, y analiza elementos como: propósito comunicativo, tipología, propiedades sintácticas, partes o estructuración cognitiva. Asimismo, revisa las sentencias como parte del género legal cases y explica su esquema principal en diversos movimientos (o segmentos de texto) (Bhatia, 1993: 135-136):

\begin{tabular}{|l|l|}
\hline $\begin{array}{l}\text { 1. Identifying the case (Encabezamiento) } \\
\text { Las causas deben ser identificadas de } \\
\text { manera clara y coherente, pues se suelen } \\
\text { citar como predecente. }\end{array}$ & $\begin{array}{l}\text { Roles v. Nathan } \\
\text { Court of Appeal [1963] 2 ALL E.R 908 }\end{array}$ \\
\hline $\begin{array}{l}\text { 2. Establishing facts of the case } \\
\text { (Antecedentes de hecho) }\end{array}$ & \\
$\begin{array}{l}\text { Se exponen los hechos de la causa que } \\
\text { son relevantes desde el punto de vista } \\
\text { jurídico. }\end{array}$ & \\
\hline $\begin{array}{l}\text { 3. Arguing the case (Argumentación, = } \\
\text { Fundamentos de derecho) }\end{array}$ & $\begin{array}{l}\text { Stating the history of the case } \\
\text { (submovimientos } \rightarrow \text { ) }\end{array}$ \\
$\begin{array}{l}\text { Ratio decidendi (or the relevant } \\
\text { principles of law) }\end{array}$ \\
\hline $\begin{array}{l}\text { 4. Pronouncing the judgment (Fallo) } \\
\text { verbo Held. Su forma es muy estándar y y } \\
\text { formulística. Puede presentar variaciones. }\end{array}$ & $\begin{array}{l}\text { The Court of Appeal held that [...] } \\
\text { Held, the warnings given to the } \\
\text { chimney sweeps by the expert on } \\
\text { behalf of the occupier of [...]. }\end{array}$ \\
\hline
\end{tabular}

Tabla 2: Elaboración propia basado en Bhatia (1993:135-136)

No obstante lo anterior, a pesar de que hemos clasificado a la sentencia inglesa como la precursora de la estadounidense, la macroestructura descrita es susceptible de presentar variaciones en el caso de los Estados Unidos, según vayamos cambiando de instancia. Además, en ocasiones las partes no están claramente diferenciadas o son subsecciones incluidas unas en otras. Estos serían, por ejemplo, los movimientos de una sentencia de un tribunal de primera instancia estadounidense, según explican Cheng, Sin y Zheng en su estudio contrastivo de sentencias chinas y norteamericanas (2008: 52): a. Heading (que, a su vez, incluye: Court; Written Case No; Parties; Judges); b. Summary; c. Facts and issues in dispute; d. Legislation applied; e. Arguments/Discussion; f. Decision/ Conclusion. 
Efectivamente, las sentencias en los Estados Unidos pueden variar en su estructura, como mantenemos, según el estado o el órgano jurisdiccional que la emite, pero se debe recalcar que todas convergen en puntos comunes: el encabezamiento (que describe los datos identificativos de la causa), el resumen de los hechos relativos a la causa o syllabus, la opinion (argumentación del órgano juzgador citando la jurisprudencia pertinente) y el fallo.

Desde un ángulo comunicativo, podemos señalar que las sentencias representan el proceso mediante el cual se aplican las normas jurídicas a los hechos del mundo real y, al mismo tiempo, dejan constancia de esos mismos hechos (Bhatia, 1993: 143). Asimismo, tienen otra misión comunicativa, que ya hemos apuntado previamente: "[th]e judgements and the rule of law [...] derived are meant to serve as precedents for subsequent cases, and are generally used as evidence in favour or against a particular line of argument for decision" (1993: 119). Por su parte, dentro de una línea conceptual Ferguson asevera que el objetivo último de este género es "[...] to transform common understanding into a tie that will, in fact, bind" (1990: 216).

En cuanto a los elementos lingüísticos y sintácticos, hallamos en las sentencias anglosajonas aquellos rasgos propios del lenguaje jurídico inglés en general, como son los latinismos, eufemismos, frases largas, sintaxis compleja, redundancia expresiva, uso de vocablos de origen francés, etc. (Alcaraz, 2002: 73-96). Igualmente, hemos de comentar que el inglés parece muy propenso a la metáfora en general (Álvarez Calleja, 1994: 469), quizá por eso en el área jurídica esta lengua es, en muchas ocasiones, más prolífica en metáforas y otras figuras que el español, el cual prefiere no recurrir a las metáforas en este ámbito, como se ha indicado previamente.

Finalmente, la intertextualidad está muy presente en este tipo de sentencia, al igual que en la sentencia española, pero con preponderancia de la alusión al precedente, cuyas referencias aparecen más a menudo que las relativas a la ley, por la ya mencionada importancia que el primero posee en la cultura jurídica anglosajona, frente a un mayor peso de la ley escrita en el derecho español. Varios de estos aspectos los ilustraremos y los comentaremos mediante ejemplos en el análisis de la opinion que ofreceremos más abajo.

\subsubsection{La opinion como género propio}

Al margen de lo comentado en el apartado anterior en cuanto a la sentencia estadounidense, se debe aclarar que existen diversos tipos de sentencia en el ordenamiento jurídico estadounidense, como judgment, decree o verdict, entre otros. Esta diversidad léxica suele depender del tipo de causa, de si se trata de un tribunal de equidad o de si es un juicio con 
jurado, por ejemplo. Por otro lado, a las sentencias del Tribunal Supremo de los Estados Unidos, la cuales nos incumben especialmente en este trabajo, se las denomina comúnmente opinions, aunque parece que también reciben el nombre de decisions, como se aprecia en el propio sitio web del tribunal ${ }^{1}$. Estas vienen definidas, entre otras, de la siguiente manera: "The judge will explain the ruling in a written document referred to as an 'opinion'. [...] explains what the case is about, discusses the relevant legal principles, and then applies the law to the facts to reach a ruling [...]" (Kerr, 2007: 51). Asimismo, algunas fuentes lexicográficas indican como equivalente de opinion "sentencia, fallo, voto" (Alcaraz \& Hughes, 2007: 408). Las opinions pueden originarse tanto en tribunales de primera instancia como en tribunales de apelación, sin distinguir causas civiles o penales. Muchos tribunales supremos estatales publican manuales de estilo para sus opinions. ${ }^{2}$ En resumen, podemos decir que, en principio, la opinion es una parte de la sentencia de tipo argumentativo, pero por el mecanismo lingüístico de la metonimia en algunos casos se pasa a llamar así a todo el documento.

La opinion parece ser un género muy concreto e independiente, ya que cuenta con una estructura característica y bien definida (Séroussi, 1998: 92), sobre todo la del Tribunal Supremo de los Estados Unidos: 1. Resumen de los hechos en orden cronológico; 2. Exposición de las cuestiones de derecho pertinentes; 3 . Análisis de los motivos contenidos en la jurisprudencia, mencionando también las fuentes del derecho; 4. Holding o norma que la jurisdicción ofrece a la cuestión de derecho suscitada; 5. Fallo en el que se confirma, se modifica o se anula la decisión de la jurisdicción inferior. Seguidamente, encontraríamos la firma del juez ponente y de los miembros que aprueban la resolución.

Por último, cabe destacar, como rasgo general que intentaremos reflejar con ejemplos en los comentarios que realizaremos más abajo, que el Tribunal Supremo estadounidense emplea "[...] un lenguaje especial, técnico e ilustrado, pero al mismo tiempo trata de ser simple e incluso localista" (Ordóñez, 2013: 14).

\footnotetext{
1 Información disponible en línea en: http://www.supremecourt.gov/opinions/info_opinions.aspx [Fecha de consulta: 30 de enero de 2015].

2 Como, por ejemplo, el New Jersey Manual On Style for Judicial Opinions. Revised and approved by the Supreme Court of New Jersey. April 22, 2004. Estructura: title; dates (argued, submitted or decided); (appeals) the court from which is taken and a citation to the opinion; Attorneys; last name of the judge authoring the opinion; "The opinion of the court was delivered by"/ Per curiam. (pp. 3-4).
} 


\section{METOdología}

Los puntos a analizar serán, básicamente, los descritos como principales convenciones de los géneros según Alcaraz, Campos y Miguélez (2001: 119), mencionados en la introducción, aunque también haremos comentarios sobre el papel de la metáfora y la cultura en este tipo de documento. La sentencia u opinion seleccionada es Adarand Constructors v. Peña (1995), con tal fin nos remitiremos parcialmente al trabajo de Vegara (2013), el cual analiza este tipo de sentencias, sobre todo en lo relativo a las metáforas que estas presentan. Cabe señalar que aquí ofrecemos un extracto de las partes más interesantes de la opinion, pues este tipo de documentos pueden llegar a tener decenas e incluso cientos de páginas y abarcar esta longitud sería inalcanzable en un estudio de estas características.

En primer lugar, describiremos, a modo de tabla comentada, la macroestructura de la opinion, para lo cual recurriremos a Kerr (2007). Seguidamente, hablaremos de su función comunicativa, así como de su léxico y su morfosintaxis, donde aportaremos numerosos ejemplos y citas. Por último, haremos hincapié en el importante rasgo de la intertextualidad, el cual es un aspecto característico en las sentencias estadounidenses. En el apartado de conclusiones comentaremos los resultados y las conclusiones específicas del análisis, las cuales darán paso a unas reflexiones finales.

Como hemos indicado en la introducción, este no pretende ser un trabajo de tipo cuantitativo, sino de tipo cualitativo-descriptivo. Nuestro objetivo es "diseccionar" una opinion siguiendo la perspectiva del género según los pasos o dimensiones sugeridos por los tres autores ya citados. Se trata, sencillamente, analizar una serie de apartados aportando ejemplos y resaltado la relevancia de cada uno, invitando a la reflexión sobre la necesidad de valorar y de tener más en cuenta el concepto de género en traducción jurídica con el fin de comprender de manera integral y más profunda el documento en cuestión.

\section{ANÁlisis de unA opINION EStAdOUNIDENSE: AdARAND Constructors V. PEÑA (1995)}

Esta sentencia deriva de una de las causas de más peso dentro de la historia de la jurisprudencia estadounidense, pues marcó un punto de inflexión en la misma. Puso fin a cierta deferencia judicial en torno a los programas federales de discriminación positiva. En este caso, se trataba de dos empresas que se presentaban a un concurso público de construcción de autopistas. La autoridad federal correspondiente le adjudicó la obra no a la empresa que presentaba la mejor oferta, sino a aquella cuyos dueños eran hispanos (Beltrán \& González, 2006: 537-538). 


\subsection{Estructura}

En este primer punto recurrimos a Kerr (2007). Su perspectiva nos resulta atractiva porque aporta un ángulo más sencillo y visual del contenido de cada parte, elabora algunos detalles y quizá se ajusta mejor a este tipo de sentencia. No obstante, llama la atención que no menciona en ningún momento la parte correspondiente al fallo. En este punto, recordamos los apuntes de Orts (2014) sobre la sentencia anglosajona, la cual tiene una estructura más flexible que la española y una clara identificación. Podemos decir que Adarand Constructors v. Peña muestra dichos rasgos. A continuación, ilustramos el modelo de Kerr con los datos de la opinion objeto de estudio (2007: 52-54):

\begin{tabular}{|c|c|}
\hline 1. Title or "Caption" & $\begin{array}{l}\text { ADARAND CONSTRUCTORS, INC. } v \text {. } \\
\text { PENA, SECRETARY OF } \\
\text { TRANSPORTATION, ET AL. }\end{array}$ \\
\hline $\begin{array}{l}\text { 2. The Case Citation } \\
\text { Grosso modo las series de letras y } \\
\text { números que identifican la causa. }\end{array}$ & $\begin{array}{l}\text { Adarand Constructors, Inc. v. Peña, } 515 \\
\text { U.S. } 200 \text { (1995) }\end{array}$ \\
\hline $\begin{array}{l}\text { 3. Autor de la opinion } \\
\text { A veces aparece el apellido del juez } \\
\text { seguido de la letra "J" (Justice) o el } \\
\text { latinismo per curiam (por el tribunal), } \\
\text { que indica que la decisión ha sido } \\
\text { unánime. }\end{array}$ & $\begin{array}{l}\text { Justice O'Connor announced the judgment } \\
\text { of the Court and delivered an opinion with } \\
\text { respect to Parts I, II, III A, III B, III D, and IV, } \\
\text { which is for the Court except insofar as it } \\
\text { might be inconsistent with the views } \\
\text { expressed in Justice Scalia's concurrence, } \\
\text { and an opinion with respect to Part III C in } \\
\text { which Justice Kennedy joins. }\end{array}$ \\
\hline $\begin{array}{l}\text { 4. The Facts of the Case } \\
\text { La primera parte del cuerpo de la } \\
\text { opinion. Aquí se describen los } \\
\text { sucesos relevantes para la causa. No } \\
\text { sigue reglas fijas (puede ser } \\
\text { corta/larga, etc.) }\end{array}$ & $\begin{array}{l}\text { In 1989, the Central Federal Lands Highway } \\
\text { Division (CFLHD), which is part of the } \\
\text { United States Department of Transportation } \\
\text { (DOT), awarded the prime contract for a } \\
\text { highway construction project in Colorado to } \\
\text { Mountain Gravel \& Construction Company. } \\
\text { Mountain Gravel then solicited bids from } \\
\text { subcontractors for the guardrail portion of } \\
\text { the contract. Adarand, a Colorado based } \\
\text { highway construction company specializing } \\
\text { in guardrail work, submitted the low bid. } \\
\text { Gonzales Construction Company also } \\
\text { submitted a bid. }\end{array}$ \\
\hline
\end{tabular}




\section{The Law of the Case \\ Esta sección consta de dos fases: la primera en la que se exponen los principios generales de derecho relevantes para casos similares (se puede citar precedentes) y que sirve de contexto. La segunda fase describe los principios generales de aplicación en el caso concreto que se está tratando. Esta parte es a todas luces "[...] the heart of the opinion" (Kerr, 2007:54).}

Las opinions pueden alcanzarse por mayoría de votos o pueden ser unánimes. Tras una majority opinion suelen incluirse las concurring 0 dissenting opinions (también denominadas concurrences y dissents, Kerr, 2007:54).

Los dissents son votos discrepantes que exponen sus argumentos en contra del fallo. Los votos concurrentes expresan su apoyo a la decisión tomada, pero con distintos argumentos jurídicos. Estos vienen después del fallo.

6. Ruling

A pesar de que Kerr no incluye el fallo, lo indicamos aquí porque forma parte esencial de la sentencia. Se puede apreciar una típica fórmula al final.
Through the 1940s, this Court had routinely taken the view in non race related cases that, "[u]nlike the Fourteenth Amendment, the Fifth contains no equal protection clause and it provides no guaranty against discriminatory Congress." Detroit Bank v. United States, 317 U.S. 329, 337 (1943); see also, e. g., Helvering v. Lerner Stores Corp., 314 U.S. 463, 468 (1941); LaBelle Iron Works v. United States, 256 U.S. 377, 392 (1921) ("Reference is made to cases decided under the equal protection clause of the Fourteenth Amendment . . . ; but clearly they are not in point.

"[...] the views expressed in the concurrence of SCALIA, J. [...]"

Tabla 3. Elaboración propia basado en Kerr (2007: 52-54)

\subsection{Función comunicativa}

Se puede decir que la función comunicativa de este texto es sobre todo informativa. Además, manifiesta las siguientes modalidades discursivas: narración y exposición en las partes de encabezamiento, antecedentes de hecho y fallo (en algunos fragmentos con gran peso de la descripción y un matiz instructivo en el último caso), así como argumentación (fundamentos de derecho u opinion). 
Igualmente, nos parece necesario recordar que, desde una óptica funcional, las sentencias del Tribunal Supremo estadounidense no se reducen a una simple concatenación de argumentos y jurisprudencia, ya que son una forma de expresión ideológica y cultural (Dickerson, 1996: 377). Superan las fronteras de la persuasión y devienen la confirmación de las creencias compartidas. Se podría decir que estas sentencias constituyen una forma de discurso con un estilo muy claro, delimitado y ritualizado, que comunica valores políticos y culturales (1996: 377).

En realidad, a pesar de que esta línea de análisis no la hemos cubierto en el presente trabajo por motivos de brevedad y concisión, no queremos restarle importancia a la necesidad de realizar un análisis tanto pragmático-discursivo, como cognitivo de este tipo de textos. Estudiar las ideas que subyacen a un texto de este calado y observar cómo se expresan en las lenguas de partida y de llegada (qué imágenes se utilizan, si abundan los modismos, las metáforas, etc.), puede constituir un análisis interesante que ayude al traductor en la toma de decisiones, iluminándole, por ejemplo, en cuestiones como la naturalidad o la claridad a alcanzar en el texto meta. Un buen primer paso para esto, sería el análisis del género, pues permite abundar en el texto y en el mensaje parte a parte, observando los elementos del mismo de manera más precisa.

Asimismo, un estudio del género de la opinion exhaustivo, el cual incluiría un análisis de su léxico y por tanto de sus metáforas, revelaría al traductor que en textos de este tipo y similares hay que ser cuidadoso con la traducción de las metáforas. He aquí un ejemplo extraído de Vegara (2013), que no aparece en la sentencia objeto de análisis, pero que resulta muy interesante para ilustrar nuestro argumento: "'A majority of the Court in Croson held that "the standard of review [...] is not dependent on the race of those burdened or benefited by a particular classification." Esta metáfora recurre a la imagen de burden o carga para hablar de una situación negativa para los miembros de ciertas razas. La elección del término burden seguramente no ha sido gratuita por parte del Tribunal: contiene una imagen negativa de peso, de carga, y posee cierta fuerza. A la hora de trasvasarlo al castellano quizá traducción literal de "cargados" u otra como "beneficiados" no suenen tan natural y presente más inconvenientes que ventajas. Este es simplemente un ejemplo de los factores que habría tomar en cuenta a la hora de elaborar la versión final del TO y que están en cierta manera relacionados con el tipo de documento. En la sección siguiente podemos hallar ejemplos de metáforas de la opinion en cuestión. 


\subsection{Dimensión léxica y morfosintaxis}

Si nos centramos en el léxico y la morfosintaxis de la opinion (con ejemplos del documento que estamos analizando), hallamos elementos característicos del lenguaje jurídico anglosajón (Alcaraz, 2002: 73-96) como son los latinismos: "CERTIORARI TO THE UNITED STATES COURT [...]"; las locuciones arcaicas: "In furtherance of the policy stated"; los adverbios compuestos: "This case therefore presents,..."; las fórmulas lingüísticas: "We conclude that [...]"; "We held"; los vocablos de origen francés: "seek damages for the loss ...", "property", "the plaintiff", "complaint"; o las expresiones metafóricas que aparecen especialmente en la fase argumentativa: "[...] "obvious that [the] program is not narrowly tailored to remedy the effects of prior discrimination [...]"; "A year later, however, the Court took a surprising turn". La redundancia expresiva y la escasez de conectores características de este tipo de lenguaje pueden apreciarse en el siguiente fragmento de Adarand:

\begin{abstract}
Two years after Bakke, the Court faced another challenge to remedial race-based action, this time involving action undertaken by the Federal Government. In Fullilove v. Klutznick, 448 U. S. 448 (1980), the Court upheld Congress' inclusion of a $10 \%$ set-aside for minority-owned businesses in the Public Works Employment Act of 1977. As in Bakke, there was no opinion ${ }^{3}$ for the Court. Chief Justice Burger, in an opinion joined by Justices White and Powell, observed that "[a]ny preference based on racial or ethnic criteria must necessarily receive a most searching examination to make sure that it does not conflict with constitutional guarantees." 448 U. S., at 491. That opinion, however, $[\ldots]$.
\end{abstract}

Se puede afirmar que, en principio, el cometido del mecanismo de repetición es el de la precisión y el de no dejar margen a la confusión. Asimismo, originalmente el motivo de la omisión de conectores era no orientar al lector del texto en ninguna dirección concreta, es decir, el mensaje debía transmitirse de forma pura; por eso para articular el cuerpo textual se recurría a la repetición de elementos léxicos, que, además, contribuía a la precisión (Crystal \& Davy, 1965: 197-202).

Por otra parte, comentábamos en apartados anteriores que, según Ordóñez, el lenguaje de este tribunal es técnico e ilustrado, pero también sencillo y simple. Al hilo de esta idea nos gustaría señalar la presencia en esta opinion de algunas metáforas interesantes. Estas forman parte del léxico del texto en cuestión y hacen referencia a importantes conceptos o ideas, pero sin tecnicismos ni complicadas expresiones puramente jurídicas.

${ }^{3}$ La cursiva es nuestra. 
Con tal fin, hemos de recurrir de nuevo al trabajo de Vegara (2013). En Adarand hallamos, por ejemplo, expresiones metafóricas como estas (2013: 495-560): "To cast this case into the outlines of racial prejudice [...]"; "[...] and Jackson filed vigorous dissents"; "[...] potentially so harmful to the entire body politic [...]"; "[...] and its history will separate benign measures from other types of racial classifications [...]". La mencionada autora describe a lo largo de su trabajo, entre otras cosas, la relevancia y la función cognitiva que expresiones como las indicadas tienen en las sentencias del Tribunal Supremo estadounidense, pues no son sólo un mero adorno textual (2013: 223). Las metáforas nos pueden aportar gran cantidad de información, aunque muchas veces son complejas de traducir, como hemos destacado en el párrafo anterior y en el apartado 5.2. Dentro de la dimensión léxica, las metáforas son un elemento importante e interesante en el que el traductor deberá detenerse a menudo y cuyo trasvase deberá sopesar, teniendo en cuenta el resto de factores que componen el texto y que se reflejan en gran medida en el análisis del género.

\subsection{Intertextualidad}

En otro orden de cosas, cabe decir que este tipo de sentencias posee un gran nivel de intertextualidad, ya que contiene continuas referencias a otras sentencias o precedentes: "Fullilove v. Klutznick, 448 U. S. 448; Lujan v. Defenders of Wildlife, 504 U. S. 555, 560 [...]", así como a textos legislativos: "Equal protection analysis in the Fifth Amendment area [...]"; "[...] all derive from the basic principle that the Fifth and Fourteenth Amendments protect persons, not groups".

Encontramos también varios nexos intratextuales que facilitan la cohesión textual y que son importantes para entender la opinion como un todo, es decir, el autor del texto a menudo remite a otras partes dentro del propio texto para recordar conceptos o ideas sin tener que volver a enunciarlas: "O'CONNOR, J., announced the judgment of the Court and delivered an opinion with respect to Parts I, II, III-A, III-B, III-D, and IV, which was for the Court except insofar as it might be inconsistent with the views expressed in the concurrence of SCALIA, J., and an opinion with respect to Part III-C. Parts I, II, III-A, III-B, III-D, [...]".

Estos elementos dentro del texto, aunque repetitivos, tiene su función y su papel, por lo que su traducción u omisión debe valorarse cuidadosamente.

\subsection{Conclusiones del análisis}

El análisis por apartados que hemos realizado, considerado a la luz de los datos teóricos aportados previamente, nos sugiere las siguientes conclusiones preliminares: 
- Quedan patentes las diversas diferencias de estilo y estructura que existen entre la sentencia española y la estadounidense. Todas ellas tienen raíz histórica y cultural, y el género textual constituye una excelente manifestación externa de ello.

- Podemos apreciar cómo los resultados de este análisis inciden directamente en la labor de traductor, concretamente, en los siguientes puntos:

a. Función comunicativa. Cabe plantearse si es realmente la misma, o si, al menos, una de las dos culturas jurídicas incluye algún matiz que sea de más peso.

b. Macroestructura. Como manifestación de la cultura jurídica de fondo y parte esencial de documento (y dadas las diferencias entre la cultura española y estadounidense): ¿hemos de dejarla siempre intacta? ¿Cuándo merece la pena adaptarla a la cultura meta y hasta qué punto?

c. La frecuencia de ciertos elementos (como los latinismos) es un factor sobre el cual reflexionar, ya que, aunque puede ser un elemento lingüístico que exista en ambos casos, su frecuencia de uso puede no ser la misma. Esta es una decisión que afecta al estilo y la naturalidad del TM.

d. Las metáforas. Como hemos visto, su traducción no siempre es evidente y, además, pueden tener un papel cognitivo nada desdeñable. Su trasvase depende de varios factores en los que no abundaremos aquí por motivos de espacio. Sin embargo, la frecuencia de uso de las metáforas en las sentencias de la cultura meta sería en este caso algo importante: en España, por ejemplo, habría que sopesar su frecuencia, ya que a priori no parece un recurso muy frecuente.

\section{CONCLUSIONES}

La breve indagación descriptiva que hemos llevado a cabo tenía como objetivo principal poner de relieve el valor que posee el análisis del género en la tarea de traducción, sobre todo de los textos altamente especializados, como son los de índole jurídica, todo ello tomando como ejemplo una opinion del Tribunal Supremo estadounidense.

Las convenciones de los géneros profesionales, como por ejemplo la función comunicativa, aportan información que puede ser de gran calado para el proceso traductológico, ya que estas son el reflejo de una cultura concreta y peculiar (Orts, 2014), en este caso jurídica. Dichas convenciones a menudo varían de una cultura a otra, como hemos observado que sucede con el género textual de la sentencia anglosajona (estadounidense) y la española.

Por tanto, la utilidad que puede tener un trabajo como el presente radica, en primer lugar, en el hecho de destacar la idea de que una labor 
previa de análisis e investigación del texto a traducir es muy importante, especialmente en un ámbito especializado. En segundo lugar, este tipo de estudios aportan un conocimiento más profundo de los textos analizados, de su organización, de su terminología y de sus posibles problemas de trasvase, entre otros. Un análisis y reflexión profunda sobre un texto o serie de textos es susceptible, asimismo, de aportar datos sobre las culturas origen y meta en cuestión (p.ej., la gran preponderancia del precedente en el mundo jurídico anglosajón, lo que indica que la parte dedicada a esto es muy importante en una sentencia, pues contendrá mucha información de valor; lo importante que es en la sentencia española que su estructura esté bien definida, pues nos proporciona datos sobre la importancia del orden y la progresión a la hora de presentar el mensaje; el escaso uso que se hace de la metáfora en algunos tipos de sentencia española, quizá porque se le considera un recurso poco serio, etc.). Esto puede ser de interés para los traductores que trabajen en el área del derecho con sentencias o con documentos similares. Siempre teniendo en cuenta otros factores muy importantes como el destinatario de la traducción, entre otros. Igualmente, el tipo de reflexión referida puede ser muy beneficiosa para los estudiantes de Traducción, ya que les permite llegar a ser conscientes de que conocer mejor el TO previamente puede repercutir en una mejor práctica traductológica.

Por último, como sugerencia para investigaciones futuras, nos parecería atractiva la realización de un estudio más profundo y amplio (quizá con un enfoque cuantitativo, si nos centramos en un elemento o aspecto específico) de este tipo de documentos, en concreto de la sentencia estadounidense, ya sea del Tribunal Supremo de la nación o de instancias inferiores, desde el concepto de género. Un estudio de estas características nos acercaría en gran medida tanto al lenguaje jurídico estadounidense como a su cultura jurídica, es decir, a su manera de entender el derecho y, por extensión, la vida.

REFERENCIAS BIBLIOGRÁFICAS

ALCARAZ, Enrique, El Inglés Jurídico. Barcelona: Ariel (1994), 2002.

—, et al., El Inglés Jurídico Norteamericano. Barcelona: Ariel, 2001.

-; Hughes, Brian, Diccionario de Términos Jurídicos. Barcelona: Ariel, 2007.

Álvarez Álvarez, Susana, "Elementos Cohesivos en el Lenguaje Jurídico: Análisis Contrastivo de las Sentencias Judiciales en Lengua Inglesa y Española". En: Actas del III Congreso Internacional de la Asociación Ibérica de Estudios de Traducción e Interpretación. La traducción del futuro: mediación lingüística y cultural en el siglo XXI, L. Pegenaute, 
J. Decesaris, M. Tricás \& E. Bernal (eds.), Barcelona: PPU. 1, 2008, pp. 407-418. Disponible en línea en:

http://www.aieti.eu/pubs/actas/III/AIETI_3_SAA_Elementos.pdf [Fecha de consulta: 25 de septiembre de 2012].

Álvarez Calleja, M. Ángeles, "El Lenguaje Económico como Fuente de Imágenes Metafóricas". En: The Golden Bowl, de Henry James". IV Encuentros Complutenses en torno a la traducción, M. Raders \& R. Martín-Gaitero (eds.). Madrid: Editorial Complutense, 1994, pp. 467476.

BARCeló, Tanagua, "La Aplicación de los Conceptos de Género, Macroestructura y Convenciones Textuales a la Traducción de Testamentos Franceses al Español". En: Entreculturas: Revista de Traducción y Comunicación Intercultural, 1, 2009, pp. 207-218.

Beltrán, Miguel; González, Julio, Las Sentencias Básicas del Tribunal Supremo de los EE.UU. de América: Selección, Traducción y Estudio Introductorio. Madrid: BOE: Centro de Estudios políticos y constitucionales, 2006.

BhatiA, Vijay K., Analysing Genre: Language Use in Professional Settings. London/New York: Longman, 1993.

BorJA, A., El Texto Jurídico Inglés y su Traducción al Español. Barcelona: Ariel, 2000.

-, "Los Géneros Jurídicos". En: Las Lenguas Profesionales y Académicas. Barcelona: Ariel, 2007.

CHENG, Le; SIN, King Kui, "Terminological Equivalence in Legal Translation: A Semiotic Approach". En: Semiotica, 172, 2008, pp. 33-45.

-, et al., "Contrastive Analysis of Chinese and American Court Judgements". En: Critical Approaches to Discourse Analysis Across Disciplines, 2, 1, 2008, pp. 49-58.

CRoss, Rupert; HARRIS, James, El Precedente en el Derecho Inglés. Madrid: Marcial Pons, 2012.

CRYSTAL, David; DAVY, Derek, Investigating English Style. London: Longman, 1965.

díaz Bautista, Antonio; Díaz-Bautista Cremades, Antonio, El Derecho Romano como Introducción al Derecho. Murcia: Diego Marín, 2010.

DICKERSON, Donna, "'Freedom of Expression' And Cultural Meaning: An Analysis of Metaphors in Selected Supreme Court Texts". En: Journal of Communications Law and Policy, 1, 1996, pp. 367-395.

FERGUSON, Robert, "The Judicial Opinion as Literary Genre". En: Yale Journal of Law and the Humanities, 2, 1990, pp. 201-219.

GarcíA, Isabel, "Los Géneros y las Lenguas de Especialidad". En: Las Lenguas Profesionales y Académicas. Barcelona: Ariel, 2006. 
GUASP, Jaime, Derecho Procesal Civil. Madrid: Instituto de Estudios Políticos, (1956), 2007.

Hatim, Basil; Munday, Jeremy, Translation: an Advanced Resource Book. London/New York: Routledge, 2004.

JENKS, Edward, El Derecho Inglés. Madrid: Reus, 1930.

KERR, Orin, "How to Read a Legal Opinion". En: The Green Bag: an Entertaining Journal of Law, 11, 1, 2007, pp. 51-63.

MALEM, Jorge, "El Lenguaje de las Sentencias". En: Reforma Judicial: Revista Mexicana de Justicia, 7, 2006, pp. 47-63.

MaYORAL, Roberto, “¿Cómo se Hace la Traducción Jurídica?”. En: Puentes, 2, 2002, pp. 9-14.

MUNDAY, Jeremy, Introducing Translation Studies. Theories and Applications. London/New York: Routledge, 2001.

ORDÓÑEZ, David, "EI Lenguaje Judicial desde una Perspectiva Comparada y Plurilingüe". En: Revista de Llengua i Dret, 59, 2013, pp. 2-41.

ORTS, Maa Ángeles, "Aproximación a la Traducción del Derecho Público: un Análisis Pragmático-discursivo de las Sentencias en el Derecho Español y el Anglosajón". Ponencia presentada en el Congreso Internacional: La traducción a debate ¿arte, mediación o profesionalización?, Universidad de Murcia, 10-12 de septiembre, 2014 (trabajo inédito).

Pérez-Prendes, José Manuel; De AzcÁrRaga, Joaquín, Lecciones de historia del Derecho Español. Madrid: Centro de Estudios Ramón Areces, S.A, 1993.

Radbruch, Gustav, El Espíritu del Derecho Inglés. Madrid: Revista de Occidente, 1985.

RiBó, Luís, Diccionario de Derecho. Barcelona: Bosch, 2005.

RODRíGuEZ, Edmundo, "El lenguaje de la Sentencia y la Exigencia de Hechos Probados en el Orden Jurisdiccional Civil y Contencioso Administrativo". Ponencia presentada en el Curso "Poder Judicial y Servicio Público", organizado por el CGPJ del 28 al 30 de noviembre de 2005. Disponible en línea en:

http://juecesdemocracia.es/publicaciones/revista/articulosinteres/Ellen guajed.pdf [Fecha de consulta: 3 de febrero de 2015].

SÉRouSSI, Roland, Introducción al Derecho Inglés y Norteamericano. Barcelona: Ariel, 1998.

SWALES, John, Genre Analysis. Cambridge University Press, 1990.

ToMÁs, José, "Las Sentencias Judiciales: Estudio y Análisis Sociolingüístico". En: Tonos Digital, 9, 2005. Disponible en línea en: http://www.um.es/tonosdigital/znum9/corpora/juridicos.htm [Fecha de consulta: 22 de mayo de 2012] 
Vegara, Laura, "Las Metáforas en los Textos Jurídicos y su Traducción al Castellano: las Resoluciones del Tribunal Supremo de los EEUU". Tesis Doctoral inédita. Alicante: Universidad de Alicante, 2013. 